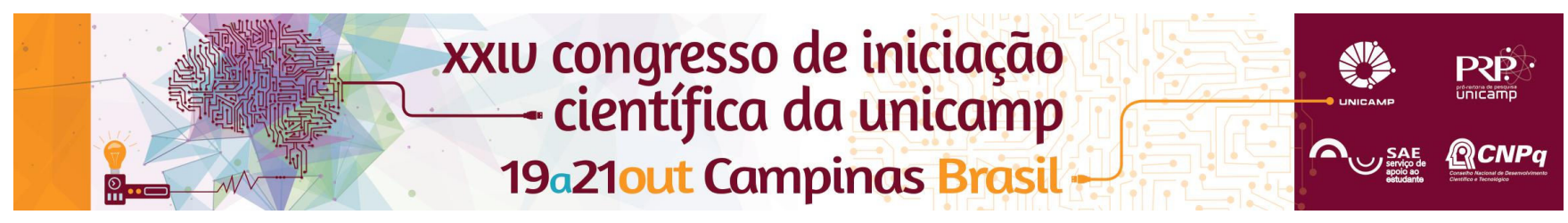

\title{
Estudo de parâmetros de interesse na produção de biosurfactantes por Bacillus subtilis.
}

\author{
Nathália G. J. Rosa*, Elias B. Tambourgi
}

\section{Resumo}

Os biosurfactantes são compostos com atividade tensoativa, produzidos por várias espécies de microrganismos. Eles apresentam grande interesse industrial, uma vez que são biodegradáveis e não tóxicos. No entanto, apesar do interesse, os biosurfactantes não conseguem competir economicamente com os surfactantes sintéticos. Neste contexto, este projeto teve como objetivo estudar os parâmetros que influenciam na produção de biosurfactantes, como temperatura, $\mathrm{pH}$, presença de glicose e glicerol.

\section{Palavras-chave:}

Biosurfactante, Bacillus subtilis, fermentação

\section{Introdução}

Os surfactantes são moléculas anfifílicas, ou seja, com porções hidrofóbicas e hidrofílicas, que reduzem a tensão superficial e a tensão interfacial ${ }^{[1]}$. Eles podem ser sintéticos, ou naturais (neste caso, chamados de biosurfactantes).

Os surfactantes sintéticos são usados para uma vasta variedade de propósitos, como emulsificação e detergência. E, atualmente, quase todos os surfactantes utilizados são quimicamente derivados de petróleo [2] Entretanto, o aumento da preocupação ambiental levou à procura por surfactantes naturais como alternativas aos produtos existentes, uma vez que os biosurfactantes são biodegradáveis e não tóxicos ${ }^{[1]}$.

Neste contexto, este projeto teve como objetivo estudar os parâmetros que influenciam na produção de biosurfactantes por Bacillus subtilis, como temperatura, $\mathrm{pH}$, presença de glicose e glicerol, visando otimizar o processo e diminuir os custos de produção ${ }^{[2]}$.

\section{Resultados e Discussão}

Os meios de cultura utilizados foram: caldo de cana e abacaxi. A melhor relação inóculo/substrato observada foi $10 \%$, em ambos os meios de cultura.

Para o meio de cultura abacaxi, os resultados demonstraram que a produção de biosurfactante é otimizada para um meio contendo $3 \%$ de glicose, sem glicerol, uma vez que houve uma maior queda na tensão superficial e alto índice de emulsificação. Estes resultados encontram-se na Figura 1 e Tabela 1.

Figura 1. Gráficos da tensão superficial em função do tempo para a produção de biosurfactante com meio enriquecido em $3 \%$ de glicose.

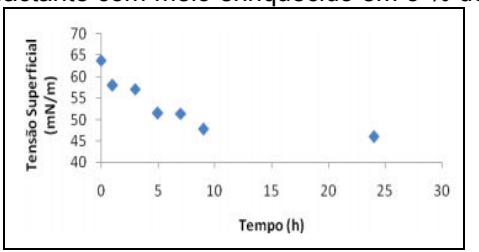

Tabela 1. Tabela com os valores dos índices de emulsificação obtidos para o biosurfactante produzido em meio enriquecido com $3 \%$ de glicose.

\begin{tabular}{|c|c|c|}
\hline Tempo (h) & Óleo de soja (\%) & Óleo de motor (\%) \\
\hline 0 & - & - \\
\hline 1 & 56,66 & 48,18 \\
\hline 3 & 66,66 & 38,46 \\
\hline 5 & 51,42 & 50 \\
\hline 7 & 54,54 & 55,88 \\
\hline
\end{tabular}

\begin{tabular}{|c|c|c|}
\hline 9 & 48,48 & 48,48 \\
\hline 24 & 52,69 & 45,6 \\
\hline
\end{tabular}

Já em relação ao meio de cultura caldo de cana, os resultados obtidos mostraram-se vantajosos para uma composição de $25 \%$ de caldo de cana no meio, sem glicerol. As análises dos testes para essa composição encontram-se na Figura 2 e Tabela 2.

Figura 2. Gráficos da tensão superficial em função do tempo para 10 $\%$ de inóculo e $25 \%$ de caldo de cana.

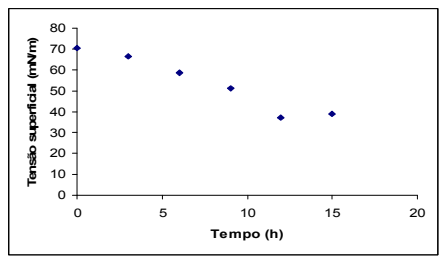

Tabela 2. Resultados obtidos para o índice de emulsificação para o meio de cultura contendo $25 \%$ de caldo de cana e $10 \%$ de inóculo.

\begin{tabular}{|c|c|c|}
\hline Tempo (h) & Óleo de Soja (\%) & Óleo de Motor (\%) \\
\hline 0 & 31,89 & - \\
\hline 3 & 58,25 & - \\
\hline 6 & 61,96 & 78,96 \\
\hline 9 & 76,23 & 71,26 \\
\hline 12 & 65,32 & 50,21 \\
\hline 15 & 72,48 & 50,89 \\
\hline
\end{tabular}

O biosurfactante produzido também foi testado em relação à temperatura, $\mathrm{pH}$ e força iônica, mostrando-se estável.

\section{Conclusões}

A produção de biosurfactantes utilizando como meio de cultura caldo de cana ou abacaxi, em presença de bactéria Bacillus subtilis, é possível. Os resultados mostraram-se satisfatórios para ambos os meios, sendo os resultados para o caldo de cana melhores quando comparados com os do abacaxi.

\section{Agradecimentos}

Os autores agradecem ao CNPq pelo apoio financeiro.

\footnotetext{
1 BUGAY, C. Biossurfactantes produzidos por Bacillus sp.: estudos de produção e caracterização. 2009. 82f. Dissertação de mestrado - Setor de Ciências Exatas, Universidade Federal do Paraná, Curitiba, 2009.

${ }^{2}$ FERNANDES, P. A. V. Produção, extração e caracterização de surfactante por Bacillus subtilis R14. 2006. 100 f. Dissertação de mestrado - Centro de ciências da saúde, Universidade Federal de Pernambuco, Recife, 2006.
} 